lagus cuniculus would puzzle not a few zoologists. The second treatise is the catalogue of passeriform bird's eggs, by Mr. Ogilvie-Grant, so well known in the department, and it is the fifth volume of the series. Both in text and plates-of which there are twenty-two, all coloured-it is worthy of the reputation of the author. The value of such a work to all ornithologists is sufficiently obvious, and the trustees have to be congratulated on this addition to the series. The third catalogue, that of the Arenicolidæ, by Dr. J. H. Ashworth, is really a monograph of the family, containing as it does the results of years of labour by the author on the structure of the group, and admirably illustrated by text-figures and fifteen plates. By his devoted and varied researches on this family and its allies, the author is rightly regarded as one of the chief authorities on the subject, and this task for the trustees of the British Museum still further emphasises that view.

From the narrative of Dr. Günther, and the three works which form the latest additions to the long roll of important publications, it is clear that the great national zoological collection is one of which the country may justly be proud; and a tribute may well, in addition, be paid to the staff, whose courteous aid is ever at the disposal of zoologists of every nation.

W. C. M.

\section{PAUL GORDAN.}

THE death of Paul Gordan, which occurred on December $2 \mathrm{I}$, has removed a mathematician of pre-eminent rank in his own particular field. When the calculus of invariants and covariants was started it was taken up with great vigour in Germany, and very important developments were effected by Aronhold, Clebsch, and Gordan respectively. Aronhold invented the symbolical method, Clebsch gave brilliant applications of it to geometry, and Gordan, besides collaborating with Clebsch, wrote numerous papers on the purely algebraic part of the theory.

Gordan's best-known, and perhaps greatest, achievement is his proof of the existence of a complete system of concomitants for any given binary form. In its original shape the proof was very laborious and difficult to grasp; even in the simpler form to which he and others reduced it, it is still very hard, and is not, perhaps, the proper and natural demonstration. However that may be, to have given the first strict proof of the theorem is an algebraic feat of the highest order. Gordan also worked out in detail the theory of transvection and "folding," ultimately arriving at formulæ which provide a sort of engine for establishing the syzygies connected with any particular binary form.

Among Gordan's other work may be mentioned his papers on finite groups, and in particular on the simple group of order 168 , and its associated curve $y^{3} z+z^{3} x+x^{3} y=0$. His book on binary forms is very valuable, and easier to read than most of his papers. The joint papers of Gordan and Clebsch are admirable: for instance, the memoir on ternary cubics in Math. Ann., vi., should be read by everyone who has mastered the easier parts of invariant-theory.

Gordan was born at Breslau in 1837 , ultimately became professor at Erlangen, and was a corresponding member of the Paris Academy of Sciences. M.

\section{NOTES.}

THE President of the Board of Agriculture and Fisheries has just appointed a departmental committee to advise the Board as to the steps which could be taken with advantage for the preservation and development of the inshore fisheries. The committee consists of Sir E. S. Howard, chairman of the Wye Board of Conservators; Sir K. S. Anderson, chairman of the Orient Steam Navigation Company; Sir S. Fay, manager of the Great Central Railway Company; Sir Norval Helme, M.P., a manufacturer; the Hon. T. H. W. Pelham, of the Harbours Department of the Board of Trade; Mr. Norman Craig, M.P.; Mr. W. Brace, a Labour M.P.; Mr. J. W. Beaumont Pease, vice-chairman of Lloyds Bank; Mr. C. Hellyer, a trawl-vessel owner; Mr. S. Bostock; and Mr. Cecil Harmsworth, M.P. Commerce and finance on the great scale are thus well represented, and no doubt the committee will be able to supplement the knowledge of the inshore fisheries which it may not possess by accepting evidence from those who do possess it. The interests of the inshore fishermen are opposed to those of the steam-trawling industry on one hand, and of the salmon fisheries on the other, and this is, no doubt, the reason why the only two fishery members of the committee are a prominent owner of steam fishing vessels and the chairman of a very important board of salmon fisheries. Those who know the highly technical occupations of the inshore fishermen will also know that the whole question of the decadence of these industries must by and by involve a scientific knowledge of the natural conditions under which inshore fishing is carried on. Yet the committee does not contain a scientific man, and it is unlikely that its members can acquire second-hand, from expert evidence, that knowledge of the "inwardness" of technical marine biology which can alone render their advice to the Board of permanent value.

Sir William Tilden, F.R.S., has been elected a corresponding member of the Imperial Academy of Sciences, St. Petersburg.

THE death is announced, at seventy years of age, of Prof. R. Collett, professor of zoology in the University of Christiania.

THE subject selected by Dr. A. J. Jex-Blake for his Goulstonian lectures, to be delivered before the Royal College of Physicians on February 25 and 27 and March 4, is "Death by Lightning and Electric Currents."

The Mexican Minister has desired the Secretary of State for Foreign Affairs to announce in this country that the Astronomical Society of Mexico has decided, beginning from 1913, to offer a medal and diploma No. 2257 , VOL. 90] 